a historieal introduction on the subject and introductory chapters on the theory (by Prof. M. E. Rose) and on the various experimental techniques involved. These should help a great deal to enable specialists in other fields of nuclear physics to assess the relevance for them of the large volume of work which appears in the proceedings of the conference.

Indeed it is arguable that the result would have been oven better if these earlier chapters could possibly have been extended from their present 73 pages out of 669 .

The book is completed by appendixes giving tables and graphs of various theoretical quantities important in this field.

G. N. FowLER

\section{ELECTRONS IN SOLIDS}

\section{Optical Properties and Electronic Structure of Metals and Alloys}

Edited by F. Abelès. (Proceedings of the International Colloquium, held at Paris, 13-16 September, 1965.) Pp. ix +643 . (Amsterdam: North-Holland Publishing Company, 1966.) $120 s$.

EXPERIMENTAL and theoretical work on band structures and Fermi surfaces has now reached the stage at which realistic models ean be used in the interpretation of metallic properties. This volume reviews recent work in the field of optical properties, covering investigations in transition and non-transition metals, rare-earth metals, liquid metals, superconductors and alloy systems. Consideration is also given to magneto-optical and photoemission techniques and to the additional information they yield about band structures. There is also a section on optical plasma effects. The impression derived from this book is of a rapidly expanding and powerful technique for the study of metals; and the introductory papers of the conference justify, but only at the postgraduate level, the claim that this book could be used as a textbook on the subject of optical propertios of metals.

\section{A. D. C. Grassie}

\section{ALLOY PHASES}

\section{Alloy Phase Equilibria}

By A. Prince. Pp. xi +290 . (Amsterdam, London and New York: Elsevier Publishing Company, 1966.) $170 s$.

Despite the revolution in the teaching of metallurgy during the past twenty or so years, the study of phase equilibria in alloy systems must remain a central topic in metallurgy curricula. The recent publication of several excellent texts on the topic supports this view and the presont volume is a valuable addition. Most of the book is devoted to binary and ternary equilibria, and includes some reference to non-equilibrium states, and the final chaptor introduces quaternary diagrams. Commondable features include the introduction to thermodynamics given in the first two chapters and the chapter describing the recent work of Palatnik and Landau on the application of topo-analytical methods to the study of phase diagrams. Although it is to some extent regrettable that no mention is made of the experimental methods used in studying phase equilibria, the text as a whole is clear and authoritative and reflects the author's enthusiasm for his subject. It is profusely illustrated with excellent line drawings and there are several references to specific alloy systems which illustrate various phase reactions.

The price of the book is likely to preclude its introduction into "essential book lists" for undergraduates, but it is to be recommended as a standard text for all metallurgical libraries and for postgraduates and others working on alloy phase rolationships.

\section{MOLECULAR ORBITALS}

Introduction of Molecular-Orbital Theory

By Arno Liberles. Pp. ix + 198. (New York and London: Holt, Rinehart and Winston, Inc., 1966.) $48 s$.

IT is nowadays widely accepted that every student of chemistry should be introduced during his second university year, if not earlier, to those aspects of quantum theory which are indispensable to an understanding of valency and the electronic structure of molecules. Such a student may be assumed to have some familiarity with the elements of atomic physics up to, say, the experimental background of the Schrödinger equation and the replacement of Bohr orbits by atomic orbitals. He would also be familiar, probably from his schooldays, with the notions of momentum, kinetic energy, sine waves and simultaneous equations, and will very likely have taken a year of university mathematics as a subsidiary subject.

Professor Liberles assumes that his students are ignorant of all this and reviews classical physics in four pages, the wave-particle dualism in two, and the theory of the atom in thirteen. He "develops" the Schrödinger equation (an important feature of the book, it is claimed) and then gives a naive but excessively long treatment of some simple solutions, taking perhaps a page to rearrange a simple equation but avoiding the points that students usually find difficult. Armed with a bare statement of the forms of the $1 s, 2 s$ and $2 p_{Z}$ orbitals, the reader meets Hückel molecular orbital theory on page 65 and the rest of the book is concerned with applications to conjugated molecules.

The quality of the exposition may be judged from excerpts such as this: "What is usually done is to select an eigenfunction arbitrarily and to assume that this is a solution of the Schrödinger equation. Then, using this function, it is possible to obtain eigenvalues". There is also this description of the chemical bond: "The bonds holding the atoms together in a molecule are molecular eigenfunctions composed of atomic eigenfunctions". Any teacher with a serious concern for his students will recoil from this garbled and damaging account of the subject. The text abounds not only in misleading statements and muddled scraps of jargon, but also in mistakes and omissions, bogus proofs and out-of-date material. The publication of this book could serve two useful purposes: it could provide students with a target for sharpening their own critical skills; and it might induce somebody to write a better one.

R. MCWEenY

\section{KINETIC THEORY}

\section{Kinetic Theory of Gases}

By Walter Kauzmann. (Thermal Properties of Matter, Vol. 1. Physical Chemistry Monograph Series.) Pp. xiii +248 . (New York and Amsterdam: W. A. Bonjamin, Inc., 1966.) $\$ 7.70$.

THe two small books on the kinetic theory which have appeared in the past few years differ greatly in scope and satisfy very different nceds. Hildebrand's Introduction is written for the average student at an elementary and fairly qualitative level and includes a section on condensed phases, while Guggenheim's Elements concentrates on gases and is probably most effective for the experienced research worker requiring a succinct résumé. In some ways this new book fills the gap. It covers roughly the same field as Guggenheim's book but does so in a way more familiar to a student of chemistry. After a substantial discussion of equations of state and the velocity distribution law, the final section of the book is devoted to a survey of molecular collisions and the molecular explanations of gaseous viscosity, diffusion and thermal conductivity. All this is also to be regarded as providing first year students 